\title{
Swimming in the tropics - navigating the dangers of marine life
}

Glover, P. and Prideaux, B. (2015) 'Swimming in the tropics - Navigating the dangers of marine life', Advances in Hospitality and Leisure, 11, pp. 41-65

\begin{abstract}
Swimming in the tropics - navigating the dangers of marine life Swimming is a popular holiday activity in tropical tourism destinations but is not risk free. Aside from the obvious risks of drowning, tropical waters harbour a number of marine animals that have the potential to injure or even kill unwary swimmers. Sharks, marine jellyfish and crocodiles may pose threats. From a destination perspective, strategies need to be implemented that firstly reduce the risk of injury and secondly care for swimmers who are injured. This paper first reports on the results of a survey of swimmers that examines a range of swimming related behaviours then proposes an action pathway model that may be implemented by destinations to reduce risk for swimmers.
\end{abstract}

Key words: Swimming, tropics, safety, stingers, crocodiles, action pathway model 


\section{Introduction}

The objective of this research was to develop a management model to assist tropical beach destinations implement strategies for enhancing swimming safety. Beaches are often promoted by tropical destinations as places for the pursuit of outdoor leisure activities, carefree fun and freedom from the concerns of the work week. Yet beaches may also be dangerous places for the unwary swimmer. Rips, marine stingers, crocodiles and sharks are some of the dangers that may be encountered particularly in the tropics (see Figure 1). Drowning and adverse encounters with marine animals are also newsworthy incidents that attract considerable, and from a destination perspective, unwelcome media attention. Given that a destination's appeal may be affected by tourists' risk perceptions (Neff, 2012), strategies that minimise risk need to be considered. Further, the addition of safety as an element in the Country Brand Index (de Nardi \& Wilks, 2007) adds another imperative for reducing risk. One problem for destinations, however, is to decide how far risk minimisation strategies should go. As Russell and Prideaux (2014) found, there is a significant visitor segment for whom risk has an appeal and measures to enhance safety may deter this segment from visiting a destination. There is also a view that safety measures and interventions will only be successful if they are recognised and observed by tourists.

In Australia research by Tourism Research Australia (cited in Williamson, Hatfield, Sherker, Brander, \& Hayen, 2012) identified going to the beach as one of the most popular tourism activities amongst both domestic and international visitors. Similar observations can be made about beaches in tropical destinations such as Bali, Goa, Florida, Mexico and the Caribbean. Specific risks associated with the beach such as drowning have been discussed in the tourism literature (Mackie, 1999; Morgan, 2006; Morgan, Ozanne-Smith, \& Triggs, 2008; Williamson, et al., 2012). However, risks associated with unintentional encounters with marine life have received relatively little attention to date.

Australia is also known for its unique wildlife and tourism providers have taken advantage of the growing desire for human-wildlife interactions (Orams, 1996 cited in Davis, Banks, Birtles, Valentine, \& Cuthill, 1997). However, the curiosity and excitement of interacting with wild animals has limitations given that many of Australia's native animals are dangerous and may 
cause considerable harm to humans including death. In areas where swimming takes place, particularly on beaches, dangers are posed by sharks, some species of stingrays and in tropical areas by crocodiles and marine jellyfish (particularly the Box Jellyfish and the Iranjiki). These dangers are vividly highlighted in travel writer Bill Bryson's (2001) humorous accounts of his experiences of travelling through Australia. For example, upon being made aware of a bluebottle jellyfish drifting past him in the water, Bryson reflects on his guide describing them as "a bit uncomfortable" (Bryson, 2001, p. 33).

"I looked at her with an expression of interest bordering on admiration. Long bus journeys are uncomfortable. Slatted wooden benches are uncomfortable. Lulls in conversations are uncomfortable. The sting of a Portuguese man-of-war [...] is agony. It occurred to me that Australians are so surrounded with danger that they have evolved an entirely new vocabulary to deal with it. [...]

'Sometimes they come in waves,' she said. 'Might be an idea to get out of the water.'

I didn't have to be told twice." (Bryson. 2001, pp. 33-34)

The following literature review first examines the concept of risk followed by a review of research into specific dangers that may be encountered at beaches including interaction with dangerous marine animals. The findings of past research are then used to build an action pathway model that provides a framework for enhancing beach safety. The model is later tested in Cairns, an Australian coastal destination that is popular among domestic and international tourists.

\section{Risk}

Risk as an issue that affects tourists has received considerable attention in the literature. Tulloch and Lupton (2003) for example state that risk is a negative phenomenon usually associated with words such as dangerous, bad and fear. According to Roehl and Fesenmaier (1992, p. 17) 'choice involves risk when the consequences associated with the decision are uncertain and some outcomes are more desirable than others'. Risk may also have a cultural bias (Hofstede, 2001; Sjoberg, 1997) or be based on gender (Morgan 2006). Other factors that affect perceptions of risk may be associated with the external environment (Sonmez \& 
Graefe, 1998) including public health, political instability and terrorism and more personal perceptions based on the individuals' psychological profile.

Tourists may be exposed to a wide range of risks either through lack of knowledge or through a decision to undertake a specific activity that has some element of risk associated with it. In northern Australia fatal encounters with crocodiles are rare but do occur. Most swimming beaches warn visitors of the dangers of crocodiles and marine stingers (see Figure 1) but this does not always prevent risk taking activities by swimmers.

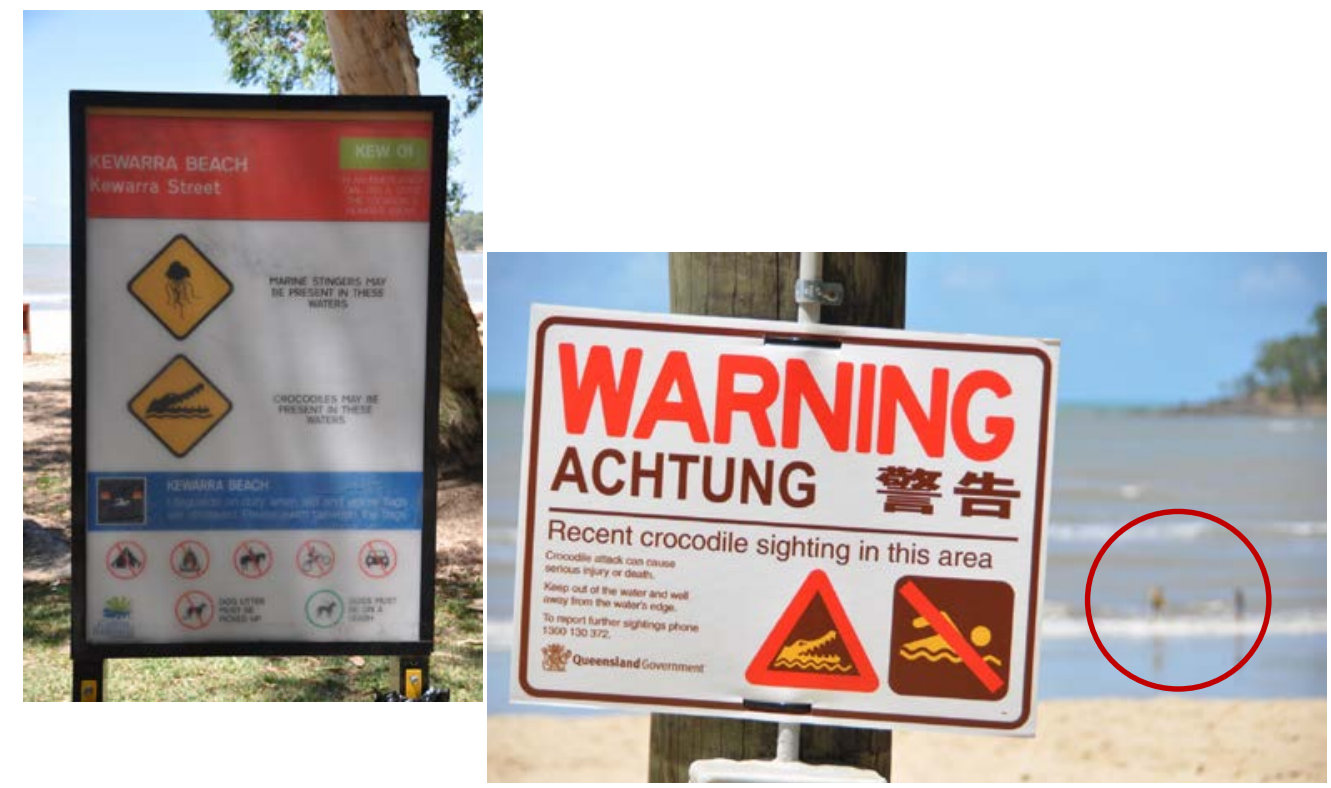

Figure 1: Beach safety signs warning swimmers of the dangers of marine stingers and crocodiles, and recent crocodile sightings. Note two swimmers (circled) can be seen in the photo on the right.

Simpson and Siguaw (2008) discussed 29 travel risk categories under the headings of five traditional risk categories: physical, performance, psychological, financial and social. Their research identified physical risks related to health and well-being as the most frequently mentioned concerns that respondents considered before deciding to take a holiday. In this category accidents were of much greater concern to potential visitors than illness. Arguably, perceived risks vary depending on the chosen destination as not all risks are equally present 
at all destinations. For example, the risk of being injured by specific animals is present in some destinations but not in others or only during specific seasons.

A number of risk frameworks have been developed to identify and classify risk including Tsaur, Tzeng and Wang (1997) and Prideaux and Master (2001). The Tsaur et al (1997) framework suggested a hierarchical structure that included transportation, law and order, hygiene, accommodation, weather, sightseeing spot and medical support. In contrast, the Prideaux and Master (2001) model identified three levels of risk cascading from macro to micro risks. However, both models failed to show how the framework could be applied to assess risk based on the selection of activities by tourists. A more recent paper by Russell and Prideaux (2014) proposed a destination risk model based on tourists' propensity to participate in risk taking activities. Three risk profiles were identified: risk taker; risk adverse; and conservatives who were not as adventurous as risk takers but were less concerned about their safety than the risk adverse group. However the model was not developed to a stage where it could be used as a policy instrument to evaluate how destinations are able to respond to the risk profile of specific groups of visitors.

In a beach setting risks arise from decisions made by tourists to participate in specific activates. For example the choice may be to swim or not to swim and be based both on the person's level of swimming skills and any problems associated with a specific beach such as rips, height of waves and presence of marine animals such as sharks, marine stingers and crocodiles.

\section{Drowning risk and beach safety}

Individuals may adopt mitigation strategies to avoid or reduce the danger of risks they perceive to exist at the destination they are visiting. Nonetheless, not all accidents and injuries are avoidable through such strategies. Transport related incidents such as drowning when a boat sinks are one of many examples. However there are many situations where exposure to situations that can lead to accidents and injuries depend on the individual tourist and how they respond to the potential for exposure to risk. Previous research for example has found males are more likely to drown than females (Franklin, Scarr, \& Pearn, 2010; Morgan, 2006) 
because they are more likely to overestimate their swimming skills and their ability to remove themselves from a dangerous situation (McCool, Ameratunga, Moran, \& Robinson, 2009). In addition, international visitors have a higher risk of drowning than domestic visitors (Franklin, et al., 2010; Morgan, et al., 2008; Wilks, 2011). Several factors contribute to this risk exposure including lack of knowledge, skills and awareness of beach safety, overestimation of their swimming ability and lack of familiarity with the coastal environment (Wilks, 2011). International visitors also tend to have less previous exposure to dangerous surf conditions and are therefore less experienced in knowing how to react when they find themselves in difficulties (Franklin, et al., 2010). Similarly, Bentley et al. (2001) found that the risk of injury tends to be higher among international visitors because they are unfamiliar with the environments in which they undertake an activity. They also participate longer in the activity, undertake unfamiliar activities and have a more relaxed attitude towards risk as a result of their underlying 'holiday mode'.

Several studies (Ballantyne, Carr, \& Hughes, 2005; Franklin et al., 2010) have examined beach safety and the behaviour of beachgoers that may expose them to the drowning risk. In Australia, a focus has been placed on the recognition of rips, adherence to safety warning and swimming between safety flags (Ballantyne et al., 2005; Franklin, et al., 2010; Hatfield, Williamson, Sherker, Brander, \& Hayen, 2010; Sherker, Williamson, Hatfield, Brander, \& Hayen, 2010; Williamson, Hatfield, Sherker, Brander, \& Hayen, 2010a, 2010b). Ballantyne et al.'s (2005) research among university students demonstrated that risky behaviour and lack of knowledge were more prevalent among international than domestic students. They were less likely to understand the meaning of warning flags placed on the beach and to correctly identify safe places to swim. Research by Franklin et al. (2010) had similar findings. While it is likely that similar risk factors play a role when assessing the dangers of unintended encounters with marine life there has been little research to support this view.

In addition to drowning, other aspects of beach safety examined in the literature include: exposure to the sun especially among children (Peattie, Clarke, \& Peattie, 2005); exposure to various forms of contamination such as sewage (Rees, 1999) and bacteria (Tseng \& Jiang, 2012) and oil spills caused by shipping accidents (Baars, 2002). Surprisingly, risks and dangers 
relating to human-animal interaction when swimming at the beach have yet to be investigated in detail.

\section{Human-animal interaction}

Research related to marine animal-human interaction has largely focused on the sustainable development of tourism activities and the potential or observed impact of these activities on the animals that are the focus of tourists' interest. Relatively little research has been undertaken into the dangers that swimmers may encounter through contact with marine animals and how these encounters can be managed to reduce risk to humans. A rare exception is research by Harrison et al. (2004) which identified a significant lack of knowledge especially among international tourists regarding the dangers of Irukandji jellyfish. The Irukandji jellyfish, named after a coastal Aboriginal tribe in Cairns is described as having a small bell that may range in size from 5 to $25 \mathrm{~mm}$ wide with four long tentacles that range in size from a few centimetres to one metre. Stings are very painful with at least two cases of death occurring after a sting (Gershwin 2007).

Previous studies into marine animal-human interaction has generally focused on marine animals that pose very little risk, provided appropriate safety protocols are in place. Several studies have examined the impacts of swimming with whale sharks (Davis, et al., 1997), dolphins (Bejder, Dawson, \& Harraway, 1999; O’Neill, Barnard, \& Lee, 2004) and whales (Kessler, Harcourt, \& Heller, 2013) as well as exploring the effect of diving on marine mammals in general (Curtin \& Garrod, 2008) and on endangered species such as the grey nurse shark (Smith, Scarr, \& Scarpaci, 2010).

Similarly, popular tourism activities such as whale watching (Curtin, 2003; Orams, 2000; Williams, Trites, \& Bain, 2002) and dolphin watching (Constantine, Brunton, \& Dennis, 2004; Lusseau \& Higham, 2004; Steckenreuter, Möller, \& Harcourt, 2012) have been scrutinised regarding their effects on animal populations and behaviour and the potential for harm to animals. The appreciation of these impacts has resulted in the implementation of various codes of practice and government policies around the world that aim to support sustainable coastal and marine tourism development (Hall, 2001). 
Some studies have discussed concerns about animal welfare resulting from marine animalhuman interaction close to the beach such as dolphin tourism in Monkey Mia, Western Australia (Smith, Samuels, \& Bradley, 2008) and stingray tourism in Hamelin Bay, Western Australia (Lewis \& Newsome, 2003; Newsome, Lewis, \& Moncrieff, 2004). These studies are different from traditional research on tourism that involves encounters with marine animals in their natural habitat as they also identify potential risks of injury for tourists that mostly result from risky and inappropriate behaviour of tourists towards the animals. For example, Newsome et al. (2004) reported on visitors hitting stingrays, touching their tails and accidentally falling or stepping on them, while Smith et al. (2008) observed chasing or hitting of dolphins and teasing but not feeding them with fish. The management of marine animalhuman interactions in both supervised and unsupervised settings is crucial for destinations to ensure not only the sustainable development of tourism activities focused on marine animals but also to avoid accidents and injuries to tourists engaging in these activities. Short of culling all dangerous marine animals, a measure that is both impractical from an operational perspective and unacceptable from an environmental perspective, adverse incidents will continue to be a possible outcome of tourists entering the habitats where these animals live. For these reasons, strategies need to be developed to help protect humans from injury with potentially dangerous marine animals however the literature is largely silent in this area.

\section{Safety interventions}

From a destination perspective, recognition of the type of risk that may be encountered by visitors is the first step to developing strategies to reduce accidents and injury. The steps required to achieve this objective are hinted at in the literature. Franklin, et al. (2010) for example suggested that injury prevention comprises four elements: education, improved design, legislation and rescue-resuscitation. A fifth element, visitor risk taking profiles, was suggested by Russell and Prideaux (2014) while a sixth element suggested by Bentley, Page and Laird (2000) focuses on policy development. Collectively, these elements suggest that actions required to achieve effective outcomes need to be sequenced and follow a defined pathway.

In one of the few papers that has examined the theory of model building in the tourism literature Getz (1986) identified two primary classes of model; theoretical which looked at 
aspects of the tourism system, and planning/management process models that generally have a capacity to solve real world problems. In a later paper that examined the idea of chaos as a driver of the tourism system McKercher (1999) observed that many models fail to work, in part because they do not recognise and capture the complexity of the system they operate in and because they often adopt a deterministic approach. McKercher (1999) further notes the general failure of models to reflect the dynamic nature of tourism, the significance of power relationships and the turbulence which the industry operates in. Overcoming these challenges requires an approach that recognises turbulence, the non-linearity of the tourism system, the influence of power (both political and commercial), the impact of large unanticipated disruptions and of critical importance, the tourist. While the models suggested by Tsaur et al. (1997) and Prideaux and Master (2001) offer much from a theoretical perspective they are unable to guide policy makers in the specific actions and the sequence they should occur in when developing strategies to enhance safety.

The proposed action pathway model outlines the sequence of actions, grouped into a pathway, that are required to achieve a specified outcome which in this research is concerned with beach swimming. The action pathway model recognises the significance of the challenges outlined above. Based on suggestions from the literature, observations of practice in a destination setting and data harvested from tourists participating in swimming, the proposed model is able to identify actions that when organised into a sequenced pathway, are able to achieve the desired outcome.

An inductive approach based on the literature reviewed above and observations of past approaches at the destination and national level was used to build the model (Figure 2). The model based on previous work by Prideaux, Thompson and Harwood (in press) is title the 'Beach safety model' and has six discrete steps:

- Step 1: Identification of visitor risk profiles;

- Step 2: Determination of destination risk profile based on activities that are available for tourists;

- Step 3: Identification of desired outcomes of interventions to improve visitor safety for both destination and tourists (i.e. reduction of drownings); 
- Step 4: Policy responses required to achieve outcomes outlined in Step 3;

- Step 5: Implementation of appropriate strategies including allocation of resources and responsibility for responsible agencies; and

- Step 6: On-going re-evaluation of each stage of the framework as a mechanism to update changes in visitor and destination risk profiles and the success of policy based on measurable outcomes.

Collectively, these actions represent the pathway that should be followed for the development and implementation of strategies to enhance safety and ensure long-term evaluation of the success of safety strategies.

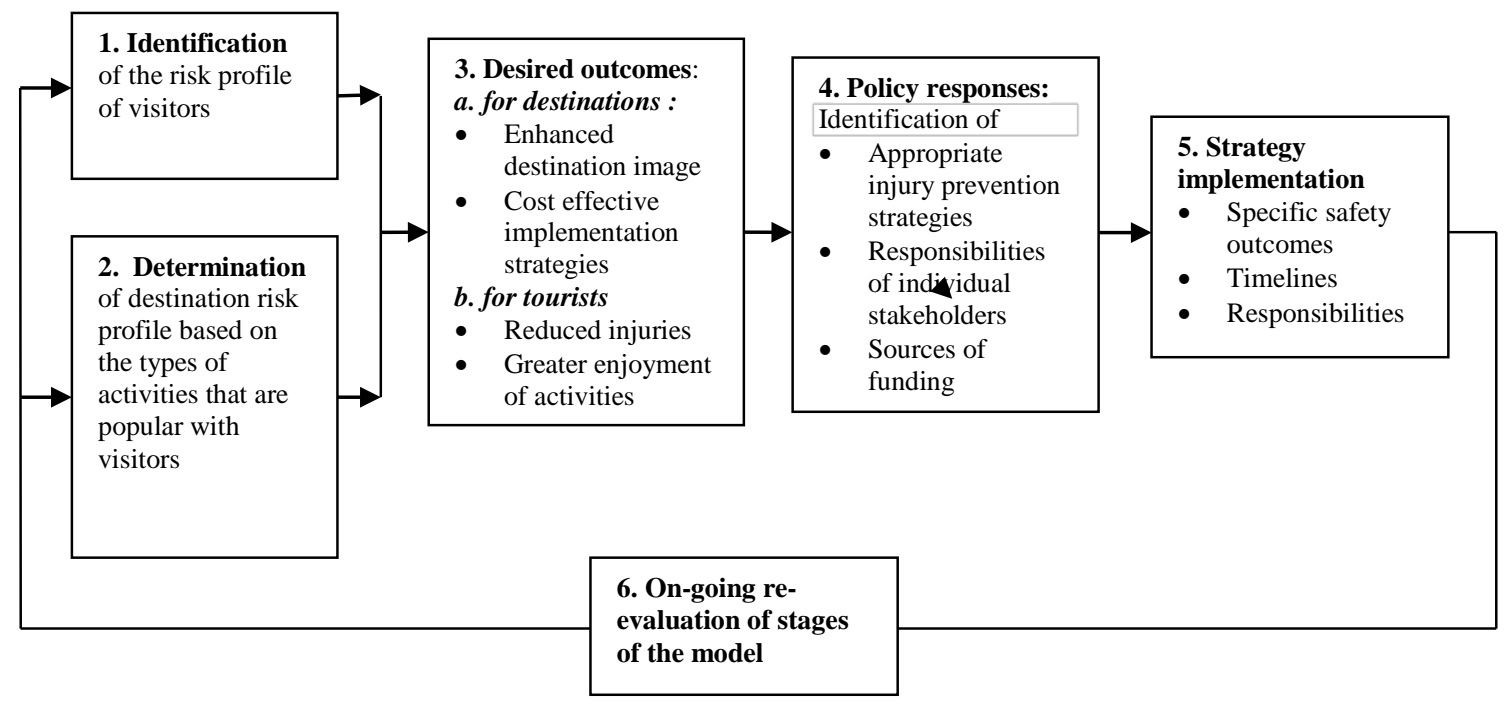

Figure 2: A six step beach safety action pathway model for enhanced beach safety

In reality, given the large number of agencies that may potentially be involved in the actions outlined in the proposed model, it is likely that many of the steps will be taken in an uncoordinated manner, or at best co-ordinated in an ad hoc manner. Moreover many of the organisations involved in the steps outlined in the model have numerous responsibilities beyond beach safety and as a consequence co-ordination may not be efficient. 
The following discussion indicates that many of the elements of the model are in fact in place in many areas of Australia. For example, following research into the causes of drowning (Steps 1 and 2 in Figure 2) (Williamson et al 2012) an education program (Steps 4 and 5) to reduce beach drowning in Australia was introduced. The development of a comprehensive rescueresuscitation capability (Step 5) has also assisted in reducing drowning rates (Franklin, et al., 2010; Wilks, 2011) to the stage where they are a rare occurrence (Lippmann \& Pearn, 2012; Wilks, 2011). Education strategies (Step 5) specifically address lack of knowledge among beachgoers. For example, since beach and swimming are a key preferences among Japanese visitors (Japan Tourism Association of Queensland, 2005 cited in de Nardi \& Wilks, 2007) water safety activities for the Japanese market have been introduced on the Gold Coast. These include among others guided beach walks which incorporate the identification of flags, rips and waves, signage and half-day surf safety education (de Nardi \& Wilks, 2007). Such education is useful not only for those visitors unable to identify risks but also for those who may overestimate their ability to cope with potential risks and are therefore more likely to place themselves in danger (White \& Hyde, 2010). In a parallel strategy the development of a national surf lifesaving system (Steps 4 and 5) funded in some destinations by the public sector and in others operated by a non-profit organisation has established a world class rescue-resuscitation service (Williamson et al., 2010b). Many popular beaches are patrolled by professional and volunteer life guards (step 5), and water conditions as well as safe places to swim are indicated on the beach by red and yellow flags. However, non-compliance is difficult to control irrespective of education, infrastructure and enforcement.

Although education and information are critical elements in preventing coastal drowning, they must be accompanied by managing access to the potential risk, provision of supervision including lifeguards and acquisition of survival skills (Wilks, 2011) as suggested by Step 5. Better design of the beach environment to improve beachgoers' safety and reducing access to risk has been achieved in particular through policy responses to shark attacks. Although there is a low probability of shark attacks the potential severity of its consequences have led to several practical, affordable and visible methods that enhance swimmers' safety (Neff, 2012). In Australia the introduction of a shark netting scheme commencing from 1935 and the more recent introduction of aerial patrols of beaches (Neff, 2012) are two strategies implemented to protect swimmers (Step 5). Although shark nets have proven effective in 
reducing shark attacks (Paterson, 1990) their implementation has raised concerns regarding the capture and entanglement of non-target species (Jefferson \& Curry, 1994) and the impact that such measures may have on the long term survivability of sharks. This debate highlights the conflict between humans and wildlife as policy initiatives must not only restore public confidence and ensure public safety but they must also take responsibility to protect wildlife and in particular endangered species (Neff, 2012). It also highlights the need for re-evaluation of strategies and measures once they have been implemented (Step 6).

Measures have also been introduced to deal with the potentially fatal impact of marine stingers, in part because they are small, difficult to catch, restricted to tropical waters and remote from the major non-tropical beaches which are the major focus of ocean swimming in Australia. The measures that have been introduced (Step 5) include the use of stinger-proof swimming enclosures during the summer when marine stingers are most prevalent, the closure of beaches in circumstances where nets are ineffective and the non-compulsory use of stinger suits (a fine mesh suit that covers the swimmer's torso, legs, feet, arms and neck) first introduced in the early 1980s (Gershwin \& Dabinett, 2009). Not all swimmers wear these suits (Fenner, 1997) in part because they reduce freedom of movement, are cumbersome to put on and in the words of one swimmer "look terrible, feels like I am in a full body condom and doesn't make me look sexy" (personal communication with a self-described beach babe, 2013).

Safety initiatives such as those outlined above may assist destinations in gaining a competitive advantage as part of a comprehensive service strategy (de Nardi \& Wilks, 2007). Nevertheless, there is a trade-off between raising awareness of risks and becoming an undesirable destination. Although overt messages may contribute to tourists feeling safe, they may also increase the perceived rather than the actual risk and contribute to a negative image and reduced visitation (Rittichainuwat, 2011). As a result destinations tend to avoid safety message that include too many hazards because they do not want to turn tourists away (Wilks, 2011). 


\section{Methods}

As stated in the introduction to this paper the aim of the research was to develop a management model to assist in reducing drownings and adverse interactions with dangerous marine animals. Model building was undertaken in three stages; stage 1 using the literature to develop the action pathway model; stage 2 used a visitor survey to elicit information about swimmers, and; stage 3 involves verifying the model. The research was undertaken in Cairns, Australia, because the destination attracts a large number of domestic and international visitors, promotes itself as a site for marine adventures that include swimming at beaches and on the Great Barrier Reef (GBR) and has to protect visitors from a range of dangerous marine animals.

Based on the results of the literature reviewed in stage 1 a preliminary model was built. The findings of the literature suggested six basic steps are required to enhance beach safety and the resulting preliminary model is illustrated in Figure 2.

To collect data a visitor survey was determined to be the most appropriate method of developing a profile of visitors' views on swimming and the precautions they adopt. Organised into three sections (demographic and trip characteristics, swimming activities at home, and swimming and related risk perceptions in Cairns) questions in the second and third part of the questionnaire were derived from the literature review and observations at the destination in consultation with the local destination management organisation. A pilot of the survey led to minor changes in the wording of some questions to ensure that they were easy to understand for speakers of English as a first and second language.

Convenience sampling (Neuman, 2006) was used to distribute and collect the self-complete questionnaire among departing domestic and international visitors at Cairns domestic airport. The research assistant used a filter question to ensure that no departing residents completed the survey. A total of 300 questionnaires were distributed of which 257 were returned. After discarding 26 incomplete questionnaires, the responses from 231 participants were used for data analysis. 
As with any survey of this nature there were a number of limitations that should be noted. These include an underrepresentation of Asian visitors because the questionnaire was distributed in English only, the relatively small percentage of visitors who travelled to the destination by land were not surveyed and there may be problems with seasonality as the survey was not conducted over a twelve month period. On a positive note however, the survey was part of a larger multi-year project that surveyed visitors at the same location using the same motivation and demographic questions. The results regarding demographics and trip characteristics show no major differences with previous survey results giving the researchers confidence that a larger sample set would have generated relatively similar results.

The study site is similar to many beach destinations in the tropics in that if offers opportunities for swimming off beaches, in pools located in accommodation establishments and in the open water when visiting coral reefs. Compared to many destinations in developing nations, the destination has a strong emphasis on safety that is backed up with extensive education campaigns, the provision of safe swimming locations based on stinger proof swimming enclosures patrolled by lifeguards, and recovery and resuscitation infrastructure including rescue helicopters, water police patrol vessels and a voluntary coast guard organisation.

\section{Survey Results \\ Demographics}

Table 1 shows that a similar number of male and female, as well as domestic and international visitors participated in the survey. The largest group of domestic visitors were intrastate visitors from Queensland, followed by visitors from New South Wales \& Australian Capital Territory, and Victoria. Overseas visitors came predominantly from North America, the UK and Germany. The majority of respondents belonged to Generation Y (born 1978-1998), followed by Baby Boomers (born 1946-1965). 
Table 1: Respondents' demographic characteristics

\begin{tabular}{|c|c|c|}
\hline \multirow[t]{2}{*}{ Gender } & Male & $45.2 \%$ \\
\hline & Female & $54.8 \%$ \\
\hline \multirow[t]{2}{*}{ Arrival from } & Australia & $54.3 \%$ \\
\hline & Overseas & $45.7 \%$ \\
\hline \multirow{4}{*}{$\begin{array}{l}\text { Usual residence } \\
\text { in Australia }\end{array}$} & Queensland & $37.6 \%$ \\
\hline & $\begin{array}{l}\text { New South Wales \& } \\
\text { Australian Capital Territory }\end{array}$ & $28.8 \%$ \\
\hline & Victoria & $27.2 \%$ \\
\hline & Rest of Australia & $6.4 \%$ \\
\hline \multirow{5}{*}{$\begin{array}{l}\text { Country of } \\
\text { residence for } \\
\text { overseas } \\
\text { visitors }\end{array}$} & USA \& Canada & $33.3 \%$ \\
\hline & UK & $29.5 \%$ \\
\hline & Germany & $19.0 \%$ \\
\hline & Other Europe & $14.3 \%$ \\
\hline & Asia & $3.8 \%$ \\
\hline \multirow[t]{4}{*}{ Generation } & Generation Y (1978-1998) & $53.6 \%$ \\
\hline & Generation X (1966-1977) & $9.8 \%$ \\
\hline & Baby Boomers (1946-1965) & $29.0 \%$ \\
\hline & $\begin{array}{l}\text { Silent Generation (pre } \\
\text { 1946) }\end{array}$ & $7.6 \%$ \\
\hline
\end{tabular}

\section{Trip Characteristics}

The vast majority of respondents travelled with at least one other person. The largest group travelled with their partner (38.7\%), followed by friends (23\%) and family members $(17.8 \%)$. It is a reflection of the respondents' generation membership that few travelled with children (6.8\%).

Despite the high proportion of repeat visitors (40.3\%) most were on their first visit to Cairns (59.7\%). Approximately one third of respondents (31.2\%) were on a short break of up to three nights, whereas almost half (49.4\%) stayed for four to seven nights. Family and friends were by far the most common source of information, used by $44.4 \%$ of respondents. Other popular sources of information included internet (28.5\%), guide books (22.9\%), travel agents $(20.6 \%)$ and previous visits (20.1\%).

\section{Motivations}

Respondents were asked to rate the importance of different destination features in their decision to visit Cairns using a Likert scale from 1 (not at all important) to 5 (very important). The results (Table 2) show that the natural environment, and in particular the ability to 
experience water and rainforest activities, were important contributors in the decisionmaking process. Visiting the Great Barrier Reef (GBR), which usually includes opportunities for swimming and snorkelling, was the most important motivation followed in fifth place by visiting beaches. As specific motivations, snorkelling, swimming and diving ranked 7th, 11th and 13th respectively. Swimming, the activity explored in this paper, was given a score of either 4 (important) or 5 (very important) by $42.7 \%$ of respondents.

Table 2: Important motivations for deciding to visit Cairns

\begin{tabular}{|l|l|c|c|c|}
\hline & Feature/ Activity & N & Mean & Std. Deviation \\
\hline 1 & Visit the Great Barrier Reef & 228 & 4.02 & 1.257 \\
\hline 2 & Good climate & 226 & 3.95 & 1.122 \\
\hline 3 & Visit the Wet Tropics rainforest & 225 & 3.83 & 1.183 \\
\hline 4 & Experience the natural environment & 216 & 3.64 & 1.086 \\
\hline 5 & Visit the beaches & 220 & 3.46 & 1.156 \\
\hline 6 & See Australian wildlife & 224 & 3.46 & 1.182 \\
\hline 7 & Snorkelling & 221 & 3.40 & 1.333 \\
\hline 8 & Walk in the rainforest & 218 & 3.31 & 1.382 \\
\hline 9 & Visit a World Heritage area & 218 & 3.23 & 1.349 \\
\hline 10 & Adventure activities & 220 & 3.14 & 1.321 \\
\hline 11 & Swimming & 218 & 3.04 & 1.303 \\
\hline 12 & Experience Aboriginal culture & 224 & 2.79 & 1.193 \\
\hline 13 & Diving & 219 & 2.70 & 1.493 \\
\hline 14 & Experience the Outback & 216 & 2.60 & 1.336 \\
\hline 15 & Go shopping & 217 & 2.55 & 1.276 \\
\hline 16 & Participate in the nightlife & 216 & 2.54 & 1.332 \\
\hline 17 & Visit friends and relatives & 218 & 2.34 & 1.516 \\
\hline 18 & To 'party' & 217 & 2.30 & 1.337 \\
\hline 19 & Business/ conference/ meeting & 215 & 1.77 & 1.260 \\
\hline
\end{tabular}

Note: The activities in italics are clearly water-related although others may have a waterelement included. Activities highlighted in grey had means greater than 3 on a 5-point Likert scale and are therefore regarded as important.

Statistically significant differences between domestic and international visitors were found for four of the five directly water-related activities, indicated by $\chi^{2} \leq 0.05$. Although the chisquare test compares distribution of responses across the 5-point Likert scale, this result is also reflected in the means. For international visitors visiting the Great Barrier Reef, visiting beaches, snorkelling and diving were more important than for domestic visitors (see Table 3), while swimming was of equal importance. 
Table 3: Comparison between important destination features according to visitor origin

\begin{tabular}{|l|c|c|c|}
\hline & $\begin{array}{c}\text { Pearson } \\
\boldsymbol{\chi}^{\mathbf{2}}\end{array}$ & $\begin{array}{c}\text { Mean } \\
\text { (domestic) }\end{array}$ & $\begin{array}{c}\text { Mean } \\
\text { (international) }\end{array}$ \\
\hline Visit the Great Barrier Reef & .000 & 3.59 & 4.55 \\
\hline Visit the beaches & .023 & 3.30 & 3.68 \\
\hline Snorkelling & .000 & 2.96 & 3.92 \\
\hline Swimming & .174 & 3.05 & 3.05 \\
\hline Diving & .000 & 2.34 & 3.14 \\
\hline
\end{tabular}

\section{Swimming at home}

For many respondents swimming is an important part of their life. The vast majority (82.2\%) stated that they swim at least several times a year and not only on holidays. Many had experience in swimming at a beach with $55.5 \%$ indicating that beaches were their preferred location for swimming while at home. This was followed by public swimming pools (43.9\%) and private swimming pools (41.9\%). Most (81.7\%) said they would swim more often if they had the opportunity.

\section{Swimming in Cairns}

The majority of respondents (70.3\%) indicated that they had been swimming during their stay in Cairns and many had done so in open water (see Figure 3), such as at the Great Barrier Reef (61.1\%), and at the beach (34.0\%). Approximately half the respondents (50.3\%) indicated that they had swum in their accommodation pool, and a significant number also reported swimming at the Lagoon (8.2\%), a free salt water swimming facility adjacent to the sea in the city's main tourist precinct. 


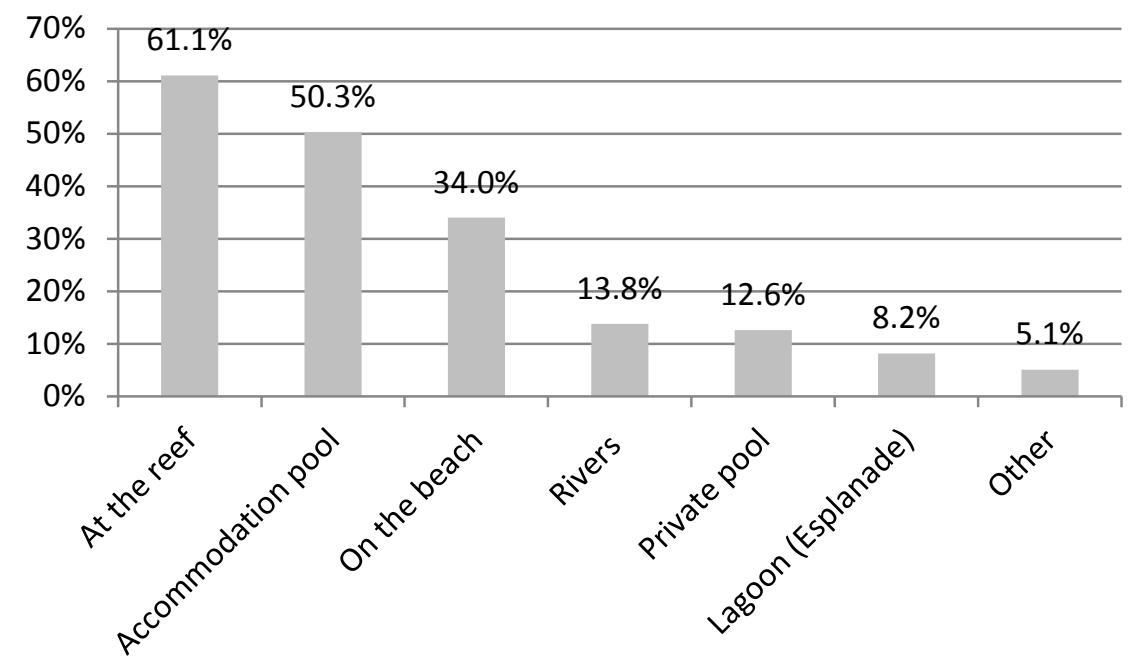

Figure 3: Facility used for swimming in Cairns

Although fewer domestic visitors (60.2\%) had participated in swimming than international visitors (82.9\%) they had been in the water more often (see Figure 4). Clearly, swimming was a popular activity with respondents.

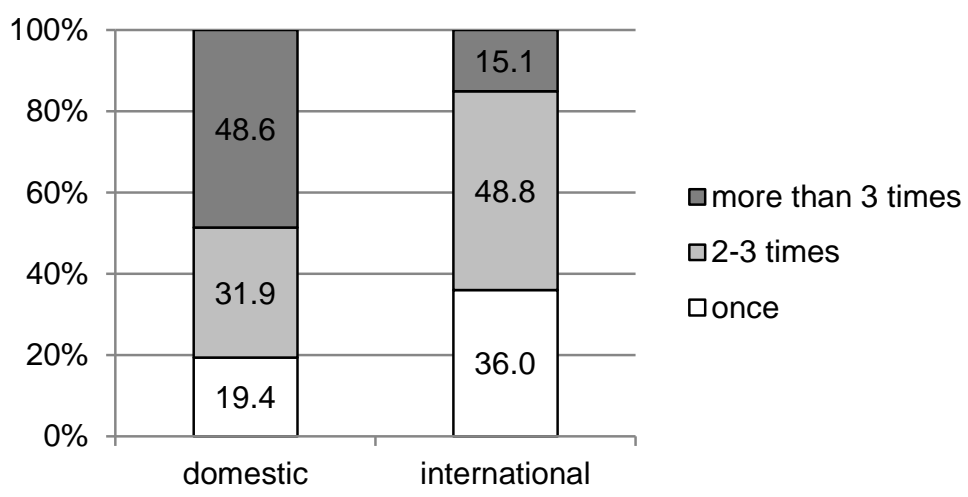

Figure 4: Frequency of swimming while in Cairns

The perceptions about the safety of swimming at Cairns beaches were divided. About half $(50.7 \%)$ regarded the activity as unsafe, while the other half $(49.4 \%)$ thought it was safe. A closer look at those who swam at the beach suggests that swimmers were aware of and accepted a certain level of risk when undertaking these activities as $30 \%$ thought that it was not at all safe/ a little unsafe. There was a clear difference between domestic and international visitors. The majority of domestic visitors (57.3\%) regarded swimming as not at 
all safe/ a little unsafe whereas the majority of international visitors (55.1\%) thought it was safe/very safe.

When asked about the danger of animals to swimmers, crocodiles were considered the most dangerous, followed by marine jellyfish, sharks and stingrays. Most respondents regarded crocodiles and marine jellyfish as very dangerous while perceptions were more divided for sharks and stingrays (see Table 4). The chi-square test found no statistically significant differences between domestic and international visitors regarding this risk perception. The vast majority (80.8\%) had been aware of the presence of jellyfish before coming to Cairns. The results were comparable between domestic and international visitors.

Table 4: Perceived risk of animals to swimmers

\begin{tabular}{|l|c|c|c|c|}
\hline $\begin{array}{l}\text { Perceived level of } \\
\text { danger }\end{array}$ & Crocodiles & $\begin{array}{c}\text { Marine } \\
\text { jellyfish }\end{array}$ & Sharks & Stingrays \\
\hline Not at all dangerous & $2.4 \%$ & $1.2 \%$ & $5.3 \%$ & $10.1 \%$ \\
\hline Somewhat dangerous & $10.1 \%$ & $15.4 \%$ & $31.0 \%$ & $39.6 \%$ \\
\hline Dangerous & $33.1 \%$ & $31.4 \%$ & $28.7 \%$ & $24.9 \%$ \\
\hline Very dangerous & $54.4 \%$ & $52.1 \%$ & $35.1 \%$ & $25.4 \%$ \\
\hline
\end{tabular}

\section{Use and recognition of safety measures}

When asked about locations for swimming, and the safety precautions they had adopted, about four-fifth $(80.7 \%)$ had swum only at a beach that was netted and approximately half (51.4\%) had used a stinger suit on the Great Barrier Reef. The proportion of domestic and international visitors who had swum at netted beaches only was comparable. In contrast, the majority of international visitors (58.8\%) had used a stinger suit while the majority of domestic visitors (58.3\%) had not.

While most visitors $(77.7 \%)$ had noticed information about safety precautions for swimming, more domestic visitors (87.3\%) than international visitors $(68.6 \%)$ had done so. The most frequently encountered type of safety information was signs (53 times), with far fewer mentions of lifeguards (6), tour guide (6) and brochures (2). In addition $61.8 \%$ confirmed that their tour operator on the Great Barrier Reef had advised them on minimising the risks of marine jellyfish. Respondents had become most aware of warnings regarding stingers/ box 
jellyfish (54) and crocodiles (39). This information was predominantly located at the beach (see Table 5) using signage of the nature illustrated in Figure 1.

Table 5: Location where safety precautions were encountered

\begin{tabular}{|l|c|}
\hline Location & Percentage \\
\hline At the beach & $71.1 \%$ \\
\hline Accommodation pool & $20.7 \%$ \\
\hline Rivers & $20.7 \%$ \\
\hline At the reef & $20.0 \%$ \\
\hline Other & $14.1 \%$ \\
\hline Promotional literature & $11.9 \%$ \\
\hline
\end{tabular}

\section{Discussion}

The aim of this research was to develop a management model able to assist destinations in developing and implementing strategies for enhancing the safety of tourists participating in swimming at beaches. The model in Figure 2 was developed using an action pathway approach based on a review of the literature and destination practice. While the model highlights the major groups of actions required it does not provide a great deal of detail about the mechanisms that might be required within each step. Specification of further details should be the responsibility of organisations within each destination.

The findings of the survey support aspects of the sequence of steps outlined in Figure 2. In relation to Step 1 of the Beach Safety model, Table 2 illustrates the importance of swimming as a motive for visiting the destination (mean=3.04) and Figure 4 highlights the number of times respondents went swimming while in the destination. Collectively, the data satisfies the requirements of Step 1. While not specifically investigated in this study, a previous study Russell and Prideaux (2014) in the same destination into the risk profile of tourists indicated that a significant number of tourists are risk takers and therefore inclined to engage in activities that may pose some element of risk. This observation strengthens the case for the production of detailed visitor risk profiles. 
Step 2 of the model is a supply side response and is in essence a catalogue of risks that may be present in the destination. In the study destination the risks relating to beach activities may include attacks by marine creatures, sunburn, heat exhaustion and heat stroke and drowning. However, the latter risk of drowning from rips tends to occur in more exposed surf beaches and is not a major issue here. While the risks outlined above are well known in the study destination, the case may not be the same in other destinations that may have fewer publically funded emergency management agencies.

The outcomes the destination wishes to achieve in relation to the types of visitors it receives and the risk profile of the destination are identified in Step 3. As part of this exercise the likelihood of specific adverse outcomes for tourists needs to be plotted as well as the cost that may be incurred to achieve these outcomes. For example, in the study destination the only way that all adverse marine animal incidents can be avoided is to close all beaches and hire security personnel to ensure that no swimming takes place. This is clearly an extreme and impractical example. A more effective manner of identifying desired outcomes is to group these outcomes into those that are visitor specific and those that relate to the tourism industry. In the case of the former, the desirable outcomes for the individual tourist are to conclude a visit to the beach without experiencing any form of injury or adverse marine animal encounter while also feeling relaxed. From a destination perspective the most desired outcome is a high level of tourist satisfaction and a lack of the type of adverse media coverage that occurs when there is a serious injury or fatality on the beach. As Morakabati et al., (2012) remind us, adverse media of the type generated by injuries and drownings has the potential to affect future visitor numbers. The outcome of the action pathway suggested through Steps 1- 3 is the adoption of a specific set of policies as illustrated as Step 4.

To achieve the policy outcomes articulated in Step 4 both the state and local governments have funded a number of strategies (Step 5) including on-going beach safety education campaigns, installation of stinger proof swimming enclosures (infrastructure) and recommendations that swimmers wear stinger suits. To ensure that public safety was given the highest priority lifeguards were given permission to close beaches if stingers (and crocodiles) were found to be present in or near the swimming enclosures. The outcome has been very few incidents of stings by marine stingers or attacks by crocodiles. The general 
success of the strategy implementation (Step 5) is illustrated in the finding that $80.7 \%$ of respondents reported only swimming at beaches that were netted and about half reported wearing stinger suits (although the use of stinger suits was higher for international respondents than domestic respondents), and $77.7 \%$ had noticed beach safety information regarding safety precautions relating to swimming.

\section{Conclusion}

The beach safety model was found to closely approximate the relatively loosely coordinated approach to swimming safety that is currently in operation in the destination. The suggested sequence of actions appears realistic and the desired outcomes of enhanced tourist and resident safety have been achieved. The adoption of the beach safety model in other coastal destinations appears justified although in the form presented in this paper it does not provide specific and detailed strategy options that may be required at a specific destination level. Given that each destination can be expected to have its own unique set of visitor segments and risk profile, this aspect of the implementation of the model is best undertaken at the destination level.

From a literature perspective, the beach safety model pulls together previous research into risk (Roehl and Fesenmaier, 1992; Sjoberg, 1997; Tulloch and Lipton 2003) and models (Prideaux and Master 2001; Tsaur et al, 1997) to suggest a practical tool that may be used at the destination level to improve swimmer safety. Moreover, the model provides a structure that can be used to identify and develop risk mitigation strategies for at-risk groups of tourists including international tourists (Wilks, 2011), international students (Ballantyne et al 2005) and males (Morgan, 2006). Implementation of strategies outlined in Step 5 for example would to a large degree eliminate the type of risk referred to by Bryson (2001) in his commentary on swimming in Australia.

The literature review also found that while there is a growing discussion in the literature on human-animal interaction, most have focused on encounters with marine animals that pose low levels of risk such as whales (Kessler et al, 2013), whale sharks (Davis et al., 1997) and other marine mammals. Research into encounters with deadly marine animals such as 
crocodiles, jelly fish and sharks has received very little attention. As Table 3 indicates education and safety warnings have worked and respondents generally had a good understanding of the potential dangers faced. Adoption of the approach suggested in the beach safety model provides a more refined approach that may be used to further reduce risk.

In terms of McKercher's (1999) observations about the problems faced in model construction including turbulence, the non-linearity of the tourism system and the influence of power (both political and commercial) as well as the impact of large unanticipated disruptions and the needs of the tourist, the beach safety model is sufficiently flexible to incorporate these elements and achieve positive outcomes. In part, the ability to continually re-evaluate all aspects of the pathways and adjust as changes occurs gives it a robustness that other models lack. Moreover, the model recognises existing relationships and processes and how these evolve; it can then draw these together in an organised way that enables more effective coordination and understanding of the consequences of decisions made by any actor at any stage of the pathway. In this aspect the model also has a 'learning system' capability that allows new understandings to be incorporated at any point in the pathway and to in turn influence how subsequent actions in the pathway need to respond.

In conclusion, the development and application of a management model format based on the action pathway approach offers an effective solution to developing safety measures at tourist beaches. In the form presented in this paper the model has a specific destination related objective but conceptually is sufficiently generic that it may be modified and expanded in detail to suit a range of destinations. 


\section{References}

Baars, B.-J. (2002). The wreckage of the oil tanker 'Erika' - human health risk assessment of beach cleaning, sunbathing and swimming. Toxicology Letters, 128(1-3), 55-68.

Ballantyne, R., Carr, N., \& Hughes, K. (2005). Between the flags: an assessment of domestic and international university students' knowledge of beach safety in Australia. Tourism Management, 26(4), 617-622.

Bejder, L., Dawson, S. M., \& Harraway, J. A. (1999). Responses by Hector's Dolphins to boats and swimmers in Porpoise Bay, New Zealand. Marine Mammal Science, 15(3), 738750.

Bentley, T., Meyer, D., Page, S., \& Chalmers, D. (2001). Recreational tourism injuries among visitors to New Zealand: an exploratory analysis using hospital discharge data. Tourism Management, 22(4), 373-381.

Bentley, B., Page, S. and Laird, S. (2000), Safety in New Zealand's Adventure Tourism Industry: The Client Accident Experience of Adventure Tourism Operators, Journal of Travel Medicine, 7(5): 239-245

Bryson, B. (2001). Down under. London: Black Swan.

Constantine, R., Brunton, D. H., \& Dennis, T. (2004). Dolphin-watching tour boats change bottlenose dolphin (Tursiops truncatus) behaviour. Biological Conservation, 117(3), 299-307. doi: http://dx.doi.org/10.1016/j.biocon.2003.12.009.

Curtin, S. (2003). Whale-Watching in Kaikoura: Sustainable Destination Development? Journal of Ecotourism, 2(3), 173-195. doi: 10.1080/14724040308668143

Curtin, S., \& Garrod, B. (2008). Vulnerability of Marine Mammals to Diving Tourism Activities. In B. Garrod \& S. Gössling (Eds.), New Frontiers in Marine Tourism: Diving Experiences, Sustainability, Management (pp. 93-113). Oxford: Elsevier.

Davis, D., Banks, S., Birtles, A., Valentine, P., \& Cuthill, M. (1997). Whale sharks in Ningaloo Marine Park: managing tourism in an Australian marine protected area. Tourism Management, 18(5), 259-271. doi: http://dx.doi.org/10.1016/S0261-5177(97)000150.

de Nardi, M., \& Wilks, J. (2007). Tourist water safety: Surf Life Saving initiatives for the Japanese inbound market. Journal of Vacation Marketing, 13(3), 275-283.

Fenner, P. J. (1997). Awareness, Prevention and Treatment of world-wide marine stings and bites. Paper presented at the International Life Saving Federation Medical/Rescue Conference Proceedings. http://www.ilsf.org/sites/ilsf.org/files/filefield/treatmentofmarinestings.pdf.

Franklin, R. C., Scarr, J. P., \& Pearn, J. H. (2010). Reducing drowning deaths: the continued challenge of immersion fatalities in Australia. Medical Journal of Australia, 192(3), 123-126.

Gershwin, L.-a., \& Dabinett, K. (2009). Comparison of Eight Types of Protective Clothing against Irukandji Jellyfish Stings. Journal of Coastal Research, 117-130. doi: 10.2112/07-0896.1.

Gershwin, Lisa-Ann (2007). "Malo kingi: A new species of Irukandji jellyfish (Cnidaria: Cubozoa: Carybdeida), possibly lethal to humans, from Queensland, Australia". Zootaxa (1659): 55-68.

Getz, D. (1986) Models in tourism planning; Towards integration of theory and practice, Tourism Management, March, 21-36

Hall, C. M. (2001). Trends in ocean and coastal tourism: the end of the last frontier? Ocean \& Coastal Management, 44(9-10), 601-618. 
Harrison, S. L., Leggat, P. A., Fenner, P. J., Durrheim, D. N., \& Swinbourne, A. L. (2004). Reported Knowledge, Perceptions, and Behavior of Tourists and North Queensland Residents at Risk of Contact With Jellyfish That Cause the "Irukandji Syndrome". Wilderness \& Environmental Medicine, 15(1), 4-10. doi: http://dx.doi.org/10.1580/1080-6032(2004)015[0004:RKPABO]2.0.CO;2.

Hatfield, J., Williamson, A., Sherker, S., Brander, R., \& Hayen, A. (2010). Improving beach safety: The science of the surf research project stage 2: Development and process evaluation of the "Don't get sucked in by the rip" campaign. Journal of Science and Medicine in Sport, 12, Supplement 2, e98.

Hofstede, G. (2001). Culture's Consequences: Comparing Values, Behaviours, Institutions, and Organisations across Nations. ( $2^{\text {nd }}$ ed). Thousand Oaks, CA: Sage.

Jefferson, T. A., \& Curry, B. E. (1994). A global review of porpoise (Cetacea: Phocoenidae) mortality in gillnets. Biological Conservation, 67(2), 167-183. doi: http://dx.doi.org/10.1016/0006-3207(94)90363-8.

Kessler, M., Harcourt, R., \& Heller, G. (2013). Swimming with whales in Tonga: Sustainable use or threatening process? Marine Policy, 39(0), 314-316. doi: http://dx.doi.org/10.1016/j.marpol.2012.12.013.

Lewis, A., \& Newsome, D. (2003). Planning for stingray tourism at Hamelin Bay, Western Australia: the importance of stakeholder perspectives. The International Journal of Tourism Research, 5(5), 331-346.

Lippmann, J. M., \& Pearn, J. H. (2012). Snorkelling-related deaths in Australia, 1994-2006. Medical Journal of Australia, 197(4), 230-232.

Lusseau, D., \& Higham, J. E. S. (2004). Managing the impacts of dolphin-based tourism through the definition of critical habitats: the case of bottlenose dolphins (Tursiops spp.) in Doubtful Sound, New Zealand. Tourism Management, 25(6), 657-667.

Mackie, I.J. (1999) Patterns of drowning in Australia, 1994-2006. Medical Journal of Australia, 171 (11-12), 587-590.

McCool, J., Ameratunga, S., Moran, K., \& Robinson, E. (2009). Taking a Risk Perception Approach to Improving Beach Swimming Safety. [Article]. International Journal of Behavioral Medicine, 16(4), 360-366. doi: 10.1007/s12529-009-9042-8

McKercher, B. (1998), A chaos approach to tourism, Tourism Management, 20, 425-434.

Morakabati, Y., Fletcher, J. and Prideaux, B. (2012) Tourism development in a difficult

environment: a study of consumer attitudes, travel risk perceptions and the termination

of demand, Tourism Economics, 18(5), doi:10.5367/te.2012.0162

Morgan, D. (2006). Analyzing the risk of drowning at surf beaches. [Article]. Tourism Review International, 10(1/2), 125-130.

Morgan, D., Ozanne-Smith, J., \& Triggs, T. (2008). Descriptive epidemiology of drowning deaths in a surf beach swimmer and surfer population. Injury Prevention, 14, 62-65.

Neff, C. (2012). Australian Beach Safety and the Politics of Shark Attacks. [Article]. Coastal Management, 40(1), 88-106. doi: 10.1080/08920753.2011.639867

Neuman, W. L. (2006). Social research methods: qualitative and quantitative approaches (6th ed.). Boston: Pearson/Allyn and Bacon.

Newsome, D., Lewis, A., \& Moncrieff, D. (2004). Impacts and risks associated with developing, but unsupervised, stingray tourism at Hamelin Bay, Western Australia. The International Journal of Tourism Research, 6(5), 305-323. 
O'Neill, F., Barnard, S., \& Lee, D. (2004). Best practice and interpretation in tourist-wildlife encounters: a wild dolphin swim tour example. Gold Coast: CRC for Sustainable Tourism.

Orams, M. B. (2000). Tourists getting close to whales, is it what whale-watching is all about? Tourism Management, 21(6), 561-569.

Paterson, R. A. (1990). Effects of long-term anti-shark measures on target and non-target species in Queensland, Australia. Biological Conservation, 52(2), 147-159. doi: http://dx.doi.org/10.1016/0006-3207(90)90123-7

Peattie, S., Clarke, P., \& Peattie, K. (2005). Risk and responsibility in tourism: promoting sunsafety. Tourism Management, 26(3), 399-408.

Prideaux, B., \& Master, H. (2001). Reducing risk factors for international visitors in destinations. Asia Pacific Journal of Tourism Research, 6(2), 24-32.

Prideaux, B., Thompson, M. \& Harwood, S. (in press) Renewing and re-invigorating settlements: A role for tourism? In A. Taylor, D. Carson, P. Ensign, L. Huskey \& R. Rasmussen (Eds.) Settlements at the edge: Remote human settlements in developed nations. Cheltenham: Edward Elgar Publishing.

Rees, G. (1999). Recreational waters and health - swimming against the tide. The Environmentalist., 19(1), 35-38.

Rittichainuwat, B. N. (2011). Tourists' Perceived Risks Toward Overt Safety Measures. Journal of Hospitality \& Tourism Research, 37(2), 199-216

Roehl, W., \& Fresenmaier, D. (1992). Risks Perceptions and Pleasure Travel. Journal of Travel Research, 30(Spring), 17-36.

Russell, C. and Prideaux, B (2014) An analysis of risk perceptions in a tropical destination and a suggested risk destination risk model, Advances in Hospitality and Leisure, 10, 91109.

Sherker, S., Williamson, A., Hatfield, J., Brander, R., \& Hayen, A. (2010). Beachgoers' beliefs and behaviours in relation to beach flags and rip currents. [Article]. Accident Analysis \& Prevention, 42(6), 1785-1804. doi: 10.1016/j.aap.2010.04.020

Simpson, P. M., \& Siguaw, J. A. (2008). Perceived travel risks: the traveller perspective and manageability. International Journal of Tourism Research, 10(4), 315-327.

Sjoberg, L. (1997), Explaining risk perception: an empirical evaluation of cultural theory, Risk Decision and Policy, Vol 2, No 2, pp 113-130.

Smith, H., Samuels, A., \& Bradley, S. (2008). Reducing risky interactions between tourists and free-ranging dolphins (Tursiops sp.) in an artificial feeding program at Monkey Mia, Western Australia. Tourism Management, 29(5), 994-1001. doi: http://dx.doi.org/10.1016/j.tourman.2008.01.001

Smith, K., Scarr, M., \& Scarpaci, C. (2010). Grey Nurse Shark (Carcharias taurus) Diving Tourism: Tourist Compliance and Shark Behaviour at Fish Rock, Australia. Environmental Management, 46(5), 699-710. doi: http://dx.doi.org/10.1007/s00267010-9561-8

Sonmez, S., \& Graefe, A. (1998a). Influence of Terrorism Risk on Foreign Tourism Decisions. Annals of Tourism Research, 25(1), 112-144.

Steckenreuter, A., Möller, L., \& Harcourt, R. (2012). How does Australia's largest dolphinwatching industry affect the behaviour of a small and resident population of IndoPacific bottlenose dolphins? Journal of Environmental Management, 97(0), 14-21. doi: http://dx.doi.org/10.1016/j.jenvman.2011.11.002 
Tsaur, S.H., Tzeng, G.H., \& Wang, K.C. (1997). Evaluating tourist risks from fuzzy perspective. Annals of Tourism Research, 24(4), 796-812.

Tseng, L. Y., \& Jiang, S. C. (2012). Comparison of recreational health risks associated with surfing and swimming in dry weather and post-storm conditions at Southern California beaches using quantitative microbial risk assessment (QMRA). Marine Pollution Bulletin, 64(5), 912-918. doi: http://dx.doi.org/10.1016/j.marpolbul.2012.03.009

Tulloch, J., \& Lupton, D. (2003). Risk and everyday life. London: Sage Publications.

White, K. M., \& Hyde, M. K. (2010). Swimming between the flags: A preliminary exploration of the influences on Australians' intentions to swim between the flags at patrolled beaches. Accident Analysis \& Prevention, 42(6), 1831-1838. doi: http://dx.doi.org/10.1016/j.aap.2010.05.004

Wilks, J. (2011). Tourist water safety: an Australian update. Travel Law Quarterly, 3(2), 100102.

Williams, R., Trites, A. W., \& Bain, D. E. (2002). Behavioural responses of killer whales (Orcinus orca) to whale-watching boats: opportunistic observations and experimental approaches. Journal of Zoology, 256(2), 255-270. doi: 10.1017/s0952836902000298.

Williamson, A., Hatfield, J., Sherker, S., Brander, R., \& Hayen, A. (2010a). Improving beach safety: The science of the surf research project stage 1: Collection of baseline data to inform a tailored intervention. Journal of Science and Medicine in Sport, 12, Supplement 2, e30.

Williamson, A., Hatfield, J., Sherker, S., Brander, R., \& Hayen, A. (2010b). Improving beach safety: The science of the surf research project stage 3: Evaluation of the effectiveness of the "Don't get sucked in by the rip" campaign. Journal of Science and Medicine in Sport, 12, Supplement 2, e32.

Williamson, A., Hatfield, J., Sherker, S., Brander, R., \& Hayen, A. (2012). A comparison of attitudes and knowledge of beach safety in Australia for beachgoers, rural residents and international tourists. [Article]. Australian \& New Zealand Journal of Public Health, 36(4), 385-391. doi: 10.1111/j.1753-6405.2012.00888.x. 